\title{
PRODUÇÃO DE PORTA-ENXERTOS CÍTRICOS EM HIDROPONIA
}

\author{
PRODUCTION OF CITRUS ROOTSTOCKS IN HYDROPONIC SYSTEM \\ WIARA DE ASSIS GOMES ${ }^{\prime *}$; NILTON NAGIB JORGE CHALFUN"; VALDEMAR FAQUIM ${ }^{\text {III; }}$ \\ PEDRO MARANHA PECHE ; WALTER DOS SANTOS SOARES FILHO ${ }^{\text {IV }}$
}

\begin{abstract}
Resumo. Uma das mais importantes etapas na produção da muda cítrica é a obtenção de porta-enxertos com identidade genética definida, em relação às variedades que se deseja propagar, e isentos de pragas. O presente experimento teve como objetivo estudar o desenvolvimento de porta-enxertos cítricos, até o ponto de enxertia, após sua transferência para sistema de cultivo hidropônico. Foi instalado e conduzido em delineamento inteiramente casualizado, em esquema fatorial 4 portaenxertos (limoeiro 'Cravo Santa Cruz', tangerineiras 'Cleópatra' e 'Sunki Tropical' e o híbrido TSKC x (LCR x TR) - 059) x 3 alturas de planta na ocasião da transferência $(0,3$ e $6 \mathrm{~cm})$, com quatro repetições e dez plantas por parcela, totalizando 480 plantas. O tratamento o (zero) correspondeu a sementes submetidas à germinação já em solução nutritiva, enquanto que os tratamentos referentes aos 3 e $6 \mathrm{~cm}$ de altura de planta foram mantidos em solução aquosa até o atingimento dessas alturas, quando, então, foram transferidos para solução nutritiva. Avaliou-se (1) a germinação das sementes através do Índice de Velocidade de Emergência (IVE) e percentagem de emergência, (2) o desenvolvimento das plantas e (3) sua produção de biomassa. O híbrido TSKC x (LCR x TR) - 059 teve o IVE reduzido quando cultivado desde a germinação em solução nutritiva. As tangerineiras podem ser semeadas já em solução nutritiva. O limoeiro ‘Cravo Santa Cruz' e o híbrido TSKC x (LCR x TR) - 059, quando transferidos com $6 \mathrm{~cm}$ de altura para a solução nutritiva, tiveram um melhor desenvolvimento em altura e diâmetro. Estes produziram maior quantitativo de biomassa. O limoeiro 'Cravo Santa Cruz' apresentou área foliar superior à dos demais porta-enxertos.
\end{abstract}

PALAVRAS-CHAVE: Citricultura. Propagação. Ambiente Protegido.

\begin{abstract}
The appropriate propagation of nucellar seedlings of citrus rootstocks varieties is one of the most important steps in the production of budded citrus trees. The present experiment aimed to investigate the development of citrus rootstocks transferred at different heights to the hydroponic system till the grafting point. The experiment was established and conducted in a completely randomized block design following a factorial scheme: 4 rootstocks ('Rangpur Santa Cruz' lime, 'Cleopatra' and 'Sunki Tropical' mandarins, and the hybrid TSKC x (LCR x TR) - 059) x 3 plant heights at the transfer stage (0, 3 and $6 \mathrm{~cm}$ ), with four replications and ten plants per plot, amounting to 480 plants. Treatment 0 (zero) corresponded to the seeds submitted to germination already in the nutrient solution whereas the treatments concerning both 3 and 6 centimeters of plant height at the transfer stage were kept up to that height in an aqueous solution then being transferred into the nutrient solution. Seed germination was evaluated through the Emergence Velocity Index (EVI) and percentage of emergence, the development of the plants as well as their biomass yield. Hybrid TSKC x (LCR x TR) - 059 had its EVI decreased when it was cultivated since germination in the nutrient solution. The mandarin varieties can be sown already in the nutrient solution. 'Rangpur Santa Cruz' lime and the hybrid TSKC x (LCR x TR) - 059 when transferred $6 \mathrm{~cm}$ high into the nutrient solution had better development both in diameter and height. These yielded a greater amount of biomass. 'Rangpur Santa Cruz' lime presented a leaf area larger than the other rootstocks.
\end{abstract}

KEYWORDS: Citrus Growing. Propagation. Protected Environment.

Agrônoma. Doutora em Fitotecnia. Universidade Federal do Rio Grande do Norte, Centro de Tecnologia - UFRN, Colégio Agrícola de Jundiaí. CEP: 59280000 , Macaíba, Rio Grande do Norte, Brasil. *Autor correspondente: wagagronomia@gmail.com ORCID ID: 0000-0001-9550-6976.

Agrônomo. Doutor em Fitotecnia. Universidade Federal de Lavras - UFLA, Departamento de Agricultura. CEP: 537200-000, Lavras, Minas Gerais, Brasil. Orcid: 0000-0002-0349-4523; 0000-0001-8865-1702. 


\section{INTRODUÇÃO}

A citricultura brasileira é a mais competitiva do mundo, com uma produção estimada para a safra $21 / 22$ de 264,14 milhões de caixas de laranja (redução de $1,39 \%$ ), em comparação ao ciclo anterior. ${ }^{1} \mathrm{~A}$ propagação comercial de espécies cítricas se dá por enxertia, devido às vantagens dessa técnica. ${ }^{2}$ Copa e porta-enxerto exercem influências recíprocas entre si, fato que pode determinar a rentabilidade do cultivo. Entre as diversas características afetadas pela relação copa/porta-enxerto, citam-se os efeitos sobre o tamanho da árvore, produtividade e qualidade de frutos, bem como tolerância a fatores bióticos e abióticos. ${ }^{3}$

Na produção de mudas certificadas, os porta-enxertos são produzidos em ambiente protegido e, dependendo da variedade e das condições de cultivo, quando esses apresentam 10 a $15 \mathrm{~cm}$ de altura, após três a cinco meses de cultivo são transplantados para os recipientes definitivos, onde é concluída a formação das mudas, fato que ocorre pela realização da enxertia, geralmente de três a seis meses após o transplantio. ${ }^{4}$

Em Minas Gerais a produção de mudas cítricas enquadra-se na categoria "Muda Fiscalizada", sendo os municípios de Dona Euzébia, Astolfo Dutra, Cataguases, Rodeiro e Piraúba, que integram a Zona da Mata, responsáveis por $53,7 \%$ das mudas produzidas nesse Estado em viveiros a céu aberto, enquanto que na região do Triângulo Mineiro, grande produtora de citros, devido à existência da Clorose Variegada dos Citros e da Morte Súbita dos Citros, toda a produção de mudas é feita em ambiente protegido, conforme Campos et al. ${ }^{5}$ Esses autores destacam a Instrução Normativa $\mathrm{n}^{\circ} 10$ da Secretaria de Defesa Agropecuária do Ministério da Agricultura, Pecuária e Abastecimento (IN $\mathrm{n}^{\circ}$ 10), instituída em 18 de março de 2005, que impede a comercialização de mudas produzidas a céu aberto com outros estados da Federação, comprometendo, portanto, a viabilidade da produção dessas mudas na Zona da Mata Mineira.

As inovadoras tecnologias para a produção de mudas devem buscar a redução do tempo e o maior controle das condições fitossanitárias. Entre os novos métodos para o aumento da produção de mudas de alta qualidade destaca-se a hidroponia, que tem sido usada em várias culturas, como espécies florestais, algumas frutíferas, além da produção de hortaliças folhosas e plantas ornamentais. Oliveira ${ }^{6}$ verificou que a produção de mudas cítricas, conduzida em sistema hidropônico, utilizando solução nutritiva proposta por Faquin e Chalfun?, mostrou-se tecnicamente viável. Contudo, Menezes ${ }^{8}$ relatou o aparecimento de um bronzeamento nas margens do limbo foliar de plântulas de limoeiro 'Cravo' (Citrus limonia Osbeck) e de citrumelo 'Swingle' [C. paradisi Macfad. x Poncirus trifoliata (L.) Raf.] 20 dias após sua transferência para a mesma solução hidropônica. Este sintoma deve-se, provavelmente, ao fato dessas plântulas se nutrirem ainda das reservas da semente e, depois de transferidas para o sistema hidropônico, a absorção de algum nutriente contido na solução pode ter levado a uma fitotoxidez.

Assim, faz-se necessário estudo complementar a fim de definir a melhor altura de transferência de plantas cítricas para soluções nutritivas, bem como obter informações sobre a produção 
de mudas cítricas em hidroponia, ainda restritas, implicando no desenvolvimento de tecnologias mais eficazes no sentido de possibilitar a produção em larga escala de porta-enxertos e mudas cítricas nessas condições. Diante do exposto,

\section{MATERIAL E MÉTODOS}

O trabalho foi realizado no Setor de Hidroponia do Departamento de Ciência do Solo da Universidade Federal de Lavras (UFLA), Município de Lavras, MG, nas coordenadas geográficas “ $21^{\circ} 13^{\prime} 55^{\prime}$ " S e “44 $57^{\circ} 43$ " W, a uma altitude de $925 \mathrm{~m}$. O clima do município é do tipo $C w b$, segundo a classificação de Köppen.

\section{Obtenção das sementes e preparo das mudas}

O experimento foi conduzido com base em quatro porta-enxertos: limoeiro 'Cravo Santa Cruz', tangerineiras 'Sunki Tropical' [C. sunki (Hayata) hort. ex Tanaka] e 'Cleópatra' (C. reshni hort. ex Tanaka) e híbrido tangerineira 'Sunki' comum x (limoeiro 'Cravo' x P. trifoliata) - 059 [TSKC x (LCR x TR) - 059]. Sementes dos mencionados porta-enxertos foram cedidas pelo Programa de Melhoramento Genético de Citros da Embrapa Mandioca e Fruticultura - PMG Citros, tendo as mesmas sido tratadas com água a $52{ }^{\circ} \mathrm{C}$ por 10 minutos e secas à sombra. Após tratadas, as sementes foram semeadas em substrato comercial Vermiculita ${ }^{\circledR}$ em tubetes plásticos de $288 \mathrm{~mL}$, os quais foram colocados em suportes próprios e levados para reservatórios plásticos, onde circulava a solução nutritiva, instalados em casa de o presente trabalho objetivou avaliar o desenvolvimento de porta-enxertos cítricos transferidos em diferentes alturas para o sistema hidropônico, até o ponto de enxertia.

vegetação. No decorrer do experimento os tubetes permaneceram em suportes próprios, sob condições hidropônicas, em casa de vegetação, onde receberam solução nutritiva proposta por Faquin e Chalfun7, até o final dos experimentos. $\mathrm{O}$ pH da solução nutritiva foi monitorado diariamente, mantido entre 5,5 e 6,5 com $\mathrm{NaOH} 5 \mathrm{~mol} \mathrm{~L}^{-1}$. A condutividade elétrica foi mantida entre 1,2 e $1,8 \mathrm{mS} / \mathrm{cm}$. As trocas da solução nutritiva foram feitas periodicamente, a cada 30 dias.

O experimento foi instalado e conduzido em delineamento inteiramente casualizado em esquema fatorial 4 porta-enxertos (limoeiro 'Cravo Santa Cruz', tangerineiras 'Cleópatra' e 'Sunki Tropical' e híbrido TSKC x (LCR x TR) 059] $\times 3$ alturas de planta na ocasião da transferência para solução nutritiva ( 0,3 e $6 \mathrm{~cm}$ ), com quatro repetições e dez plantas por parcela, totalizando 480 plantas. O tratamento o (zero) correspondeu as sementes submetidas à germinação já na solução nutritiva, enquanto os tratamentos referentes a 3 e $6 \mathrm{~cm}$ de transferência foram mantidos em solução aquosa até atingirem as respectivas alturas, sendo então transferidos para solução nutritiva.

Foram avaliados os seguintes caracteres: tempo para início da emergência das plântulas, tempo transcorrido entre 
a primeira e última plântula emergida, percentagem de germinação, tempo em dias após a semeadura (DAS) que concentrou a maior percentagem de emergência de plântulas e Índice de Velocidade de Emergência (IVE), de acordo com Maguire ${ }^{9}$, sendo: IVE $=\left(E_{1} / \mathrm{N} 1\right)+\left(E_{2}\right.$ $/ N 2)+\ldots+(E n / N n)$, onde: $E 1=$ número de plântulas emergidas; $\mathrm{N} 1$ = número de dias decorridos da semeadura até a primeira contagem; $\mathrm{E}_{2}$ = número de plântulas emergidas na segunda contagem; $\mathrm{N}_{2}=$ número de dias decorridos da semeadura até a segunda contagem; $\mathrm{n}=$ última contagem.

\section{Características avaliadas após transfe- rência para solução nutritiva}

Realizou-se avaliação quinzenal do diâmetro e da altura dos porta-enxertos. 0 diâmetro do caule foi tomado ao nível do substrato na base do caule (colo da planta: zona de transição entre o caule e a raiz), medido com um paquímetro milimetrado e a altura (comprimento do caule) das plantas por meio de régua milimetrada, tomada desde a base do caule ao nível do substrato até a última gema apical.

Foi monitorado e determinado o tempo necessário para os porta-enxertos atingirem $o$ ponto de repicagem $(15 \mathrm{~cm}$ de altura) e ponto de enxertia, o qual foi considerado entre 5 e $6 \mathrm{~mm}$, medido a 10

\section{RESULTADOS E DISCUSSÃO}

O início da emergência das plântulas deu-se aos 30 DAS, para todos os genótipos, tanto em solução aquosa como nutritiva, à exceção do limoeiro 'Cravo Santa Cruz’ que, em solução nutritiva, iniciou a cm do colo.

Após 150 dias do plantio, quando $60 \%$ dos porta-enxertos atingiram 0 ponto de repicagem, foram escolhidas aleatoriamente, dentro de cada tratamento, cinco plantas, as quais foram utilizadas para determinação da área foliar $(\mathrm{AF})$, que foi dada pela relação entre a área de 15 discos foliares e suas respectivas massas com a massa total da folha. ${ }^{10}$

Foi determinada a massa seca das plantas amostradas, separando-se raízes e parte aérea (caule e folhas), as quais foram levadas à estufa a $72^{\circ} \mathrm{C} / 72 \mathrm{~h}$, sendo após pesadas separadamente para o cálculo de partição de biomassa. A massa seca total foi dada pelo somatório das massas de raízes + parte aérea. A razão massa seca raiz/parte aérea foi calculada pela divisão da massa seca das raízes pela massa seca da parte aérea (caule + folhas).

\section{Análise Estatística}

Os dados foram submetidos à análise de variância pelo Teste F. Para as variáveis qualitativas, foi aplicado o Teste de Tukey a $5 \%$ de probabilidade, realizado por meio do aplicativo Sisvar. ${ }^{11}$ Para as variáveis quantitativas procedeu-se um estudo de regressão polinomial ao nível de $5 \%$, utilizando-se do aplicativo $R$ ( $R$ DEVELOPMENT CORE TEAM, 2010). ${ }^{12}$

emergência aos 36 DAS. Pode-se observar que o tempo transcorrido entre a primeira e a última plântula emergidas para as tangerineiras 'Cleópatra' e 'Sunki Tropical' foi de 22 e 24 DAS, em solução aquosa e 
nutritiva, respectivamente, enquanto para o limoeiro 'Cravo Santa Cruz' esse tempo foi de 22 e 16 DAS, em solução aquosa e nutritiva, respectivamente. A emergência das plântulas do híbrido TSKC x (LCR x TR) - 059 ocorreu num intervalo de 24 DAS em ambas as soluções (Figura 1).

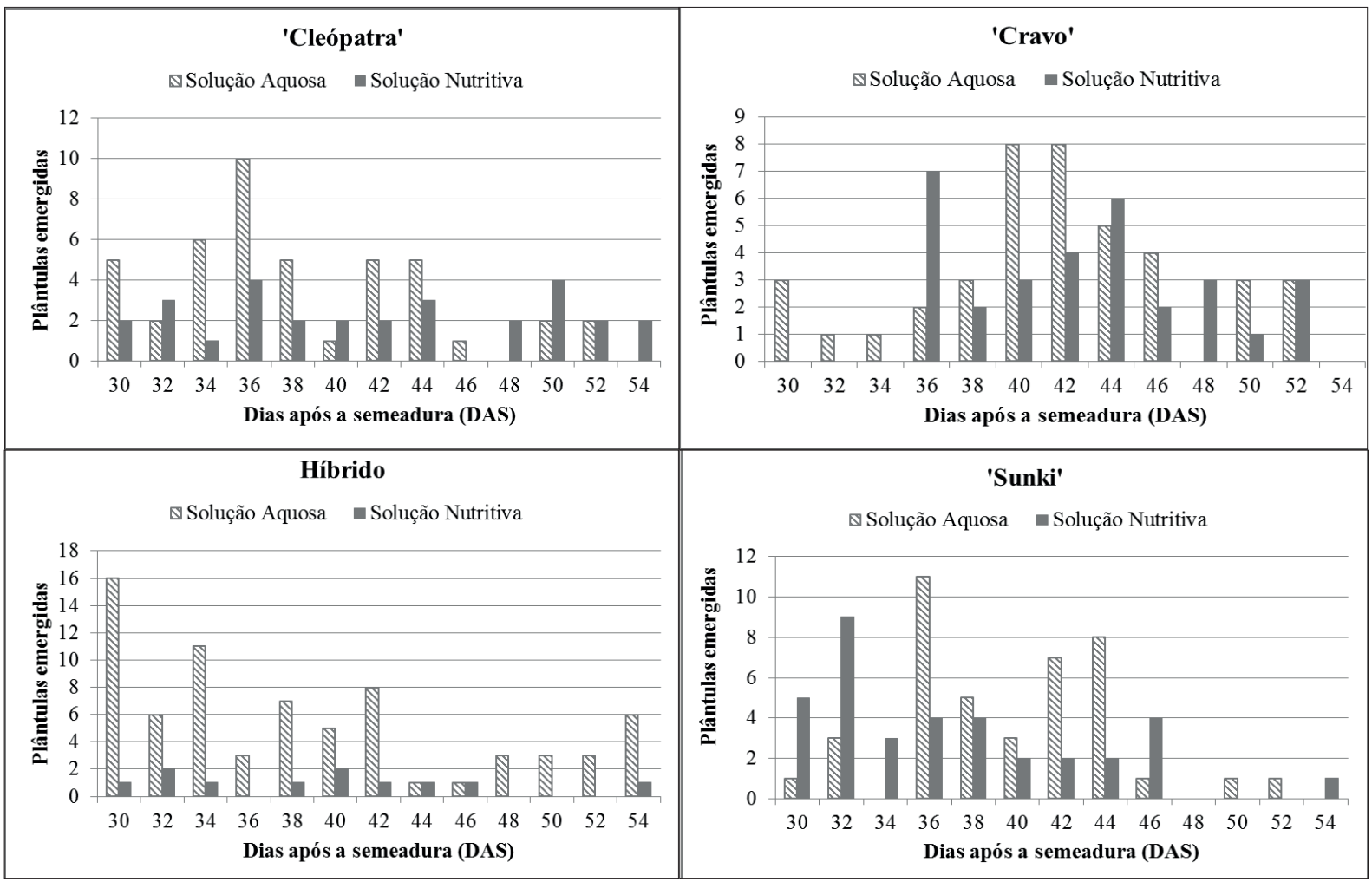

FIGURA 1: Distribuição, no tempo, da emergência de plântulas de variedades porta-enxerto de citros em soluções aquosa e nutritiva. Lavras-MG, 2012.

Em solução aquosa, a 'Sunki Tropical' apresentou o maior percentual de plântulas emergidas (75\%) sendo, porém, estatisticamente igual ao constatado em 'Cravo Santa Cruz' e em 'Cleópatra'. Provavelmente, as sementes dessas variedades encontravam-se com um maior quantitativo de reservas. As sementes do híbrido TSKC x (LCR x TR) - 059 apresentaram menor percentagem de emergência (22,91\%), sendo esta estatisticamente inferior ao verificado nas demais variedades portaenxerto; já em solução aquosa, o híbrido foi estatisticamente superior às demais variedades porta-enxerto, com um total de $82,11 \%$ de plântulas emergidas (Tabela 1). Jabur e Martins ${ }^{13}$ obtiveram os maiores valores para a emergência de plântulas de limoeiro 'Cravo' (71,25\%) e tangerineira 'Cleópatra' (50\%) quando estas variedades porta-enxerto foram cultivadas apenas com vermiculita. Ainda na Tabela 1, constata-se que não houve diferença estatística entre as variedades porta-enxerto quando se analisou o IVE em solução nutritiva, com média de 0,17. Quando em solução aquosa, o híbrido TSKC $\times($ LCR $\times$ TR) - 059 superou os demais porta-enxertos, apresentando a tangerineira 'Sunki Tropical' o menor valor relacionado a esse caráter (Tabela 1). Siqueira 
et al. $^{14}$ verificaram menor IVE em sementes não armazenadas da tangerineira 'Cleópatra', mesmo quando essas sementes tiveram grau de umidade superior ao mostrado pelas sementes do limoeiro 'Cravo'.

TABELA 1: Emergência e Índice de Velocidade de Emergência (IVE) de plântulas de variedades porta-enxerto de citros em soluções nutritiva e aquosa. Lavras-MG, 2012

\begin{tabular}{lcccc}
\hline \multirow{2}{*}{\multicolumn{1}{c}{ Porta-enxertos* }} & \multicolumn{2}{c}{ Emergência (\%) } & \multicolumn{2}{c}{ IVE } \\
\cline { 2 - 5 } & \multicolumn{2}{c}{ Soluções } & \multicolumn{2}{c}{ Soluções } \\
\cline { 2 - 5 } & Nutritiva & Aquosa & Nutritiva & Aquosa \\
\hline Tangerineira 'Sunki Tropical' & $75,00 \mathrm{a}$ & $41,73 \mathrm{~b}$ & $0,25 \mathrm{a}$ & $1,08 \mathrm{c}$ \\
Tangerineira 'Cleópatra' & $58,33 \mathrm{a}$ & $44,31 \mathrm{~b}$ & $0,17 \mathrm{a}$ & $1,16 \mathrm{bc}$ \\
Limoeiro 'Cravo Santa Cruz' & $68,75 \mathrm{a}$ & $47,59 \mathrm{~b}$ & $0,19 \mathrm{a}$ & $1,31 \mathrm{~b}$ \\
Híbrido TSKC x (LCR x TR) - 059 & $22,91 \mathrm{~b}$ & $82,11 \mathrm{a}$ & $0,07 \mathrm{a}$ & $1,95 \mathrm{a}$ \\
\hline C.V. (\%) & \multicolumn{2}{c}{22,05} & \multicolumn{3}{c}{14,03} \\
\hline DMS & \multicolumn{2}{c}{28,04} & \multicolumn{2}{c}{0,19} \\
\hline
\end{tabular}

*Tangerineira ‘Sunki Tropical’ [Citrus sunki (Hayata) hort. ex Tanaka]; tangerineira 'Cleópatra' (C. reshni hort. ex Tanaka); limoeiro ‘Cravo Santa Cruz' (C. limonia Osbeck); TSKC: tangerineira 'Sunki’ comum; LCR: limoeiro 'Cravo'; TR: Poncirus trifoliata (L.) Raf.; Médias seguidas de mesmas letras, nas colunas, não diferem pelo teste de Tukey a $5 \%$ de probabilidade.

Quanto à evolução do desenvolvimento do diâmetro do caule das variedades porta-enxerto estudadas (Figura 2), verificou-se que o limoeiro 'Cravo Santa Cruz' e o híbrido TSKC x (LCR x TR) - 059, quando transferidos para solução nutritiva aos $6 \mathrm{~cm}$ de altura de planta, atingiram o ponto de enxertia, de $5 \mathrm{~mm}$, tomado à 10 cm do colo da planta, aos 150 dias após a transferência (DAT). Esse resultado coincide com os de Serrano et al. ${ }^{15}$, os quais, analisando a produção de portaenxertos de 'Cravo', obtiveram o ponto de enxertia médio aos 154 DAR (dias após a repicagem), verificando-se o mesmo em estudo realizado por Grassi Filho et al. ${ }^{16}$, que obtiveram o ponto de enxertia aos 150 DAR.

Em todas as variedades portaenxerto estudadas, o diâmetro do caule evoluiu seguindo o modelo linear para todas as alturas de transferência estudadas. A tangerineira 'Cleópatra' apresentou a maior taxa de crescimento, de $0,37 \mathrm{~mm}$ a cada período avaliado, quando a altura inicial foi $6 \mathrm{~cm}$ (Figura 2). Essa mesma tendência foi seguida pelo limoeiro 'Cravo Santa Cruz' (0,51 mm), híbrido TSKC x (LCR $x$ TR $)$ - $059(0,43 \mathrm{~mm})$ e pela tangerineira 'Sunki Tropical' $(0,38 \mathrm{~mm})$ a cada período avaliado, quando a altura de transferência foi $6 \mathrm{~cm}$ (Figura 2). Provavelmente, as plantas transferidas para a solução nutritiva com essa altura já apresentavam uma maior taxa fotossintética, o que proporcionou um maior crescimento, em comparação com o verificado quando a transferência para cultivo em solução hidropônica deu-se com as demais alturas de planta.

$\mathrm{Na}$ Figura 3 são apresentados os resultados da altura de plantas. O limoeiro 'Cravo Santa Cruz' e o híbrido TSKC x (LCR $x$ TR) - 059, quando transferidos para solução nutritiva aos $6 \mathrm{~cm}$, atingiram 0 ponto de repicagem, em média, aos 90 DAT; as tangerineiras tiveram desempenho equivalente, porém quando foram cultivadas desde o início do ensaio em 
solução nutritiva. Convém ressaltar que em produção comercial de mudas cítricas, o ponto de repicagem é obtido, em média, aos 150 DAR. ${ }^{3}$

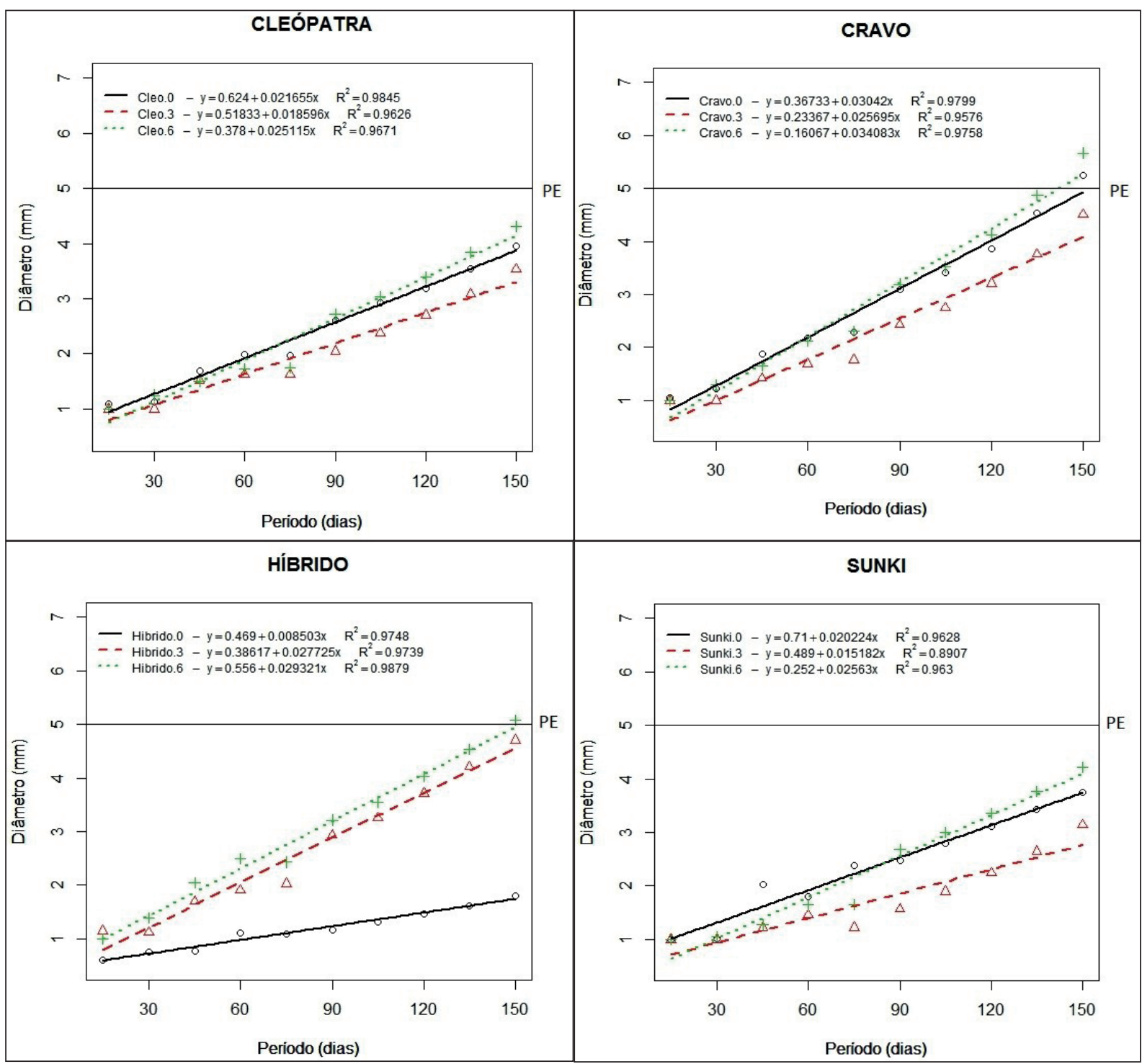

FIGURA 2: Diâmetro de seedlings (plantas oriundas da germinação de sementes ou pés-francos) de variedades porta-enxerto de citros transferidos em diferentes alturas de planta $(0,3$ e $6 \mathrm{~cm})$ para sistema de cultivo hidropônico, em dez períodos de avaliação. PE: Ponto de Enxertia. Lavras-MG, 2012.

Todas as variedades porta-enxerto estudadas cresceram em altura obedecendo a um modelo linear, em todas as alturas de transferência estudadas. As tangerineiras 'Cleópatra' e 'Sunki Tropical' apresentaram maiores taxas de crescimento (1,636 e $1,440 \mathrm{~cm}$, respectivamente) a cada período avaliado, quando a altura de transferência foi zero, ou seja, para essas variedades a semeadura pode ser feita diretamente em solução nutritiva. O 'Cravo Santa Cruz' obteve melhor taxa de crescimento de $(3,063 \mathrm{~cm})$ a cada período avaliado, quando as plantas foram transferidas com $6 \mathrm{~cm}$. Para o híbrido, a maior taxa de crescimento $(2,462 \mathrm{~cm})$ foi alcançada pelas plantas com 
a altura de transferência de $3 \mathrm{~cm}$ (Figura 3). Segundo Jabur e Martins ${ }^{13}$, as diferenças entre o desenvolvimento dos porta-enxertos é normal em razão das características de cada variedade. A esse respeito, por exemplo, esses autores comentam que o limoeiro 'Cravo' é conhecido por seu maior vigor e a tangerineira 'Cleópatra', apesar do crescimento em altura de planta, tem dificuldades quanto ao engrossamento do caule. Em reforço a esses comentários, Teixeira et al. ${ }^{17}$ também enfatizaram as diferenças de crescimento inerentes a cada espécie cítrica, relatando que a tangerineira 'Sunki', quando comparada com o citrange 'FEPAGRO C37'e com o 'Trifoliata' ( $P$. trifoliata), apresentou crescimento menos vigoroso em altura e diâmetro do caule.

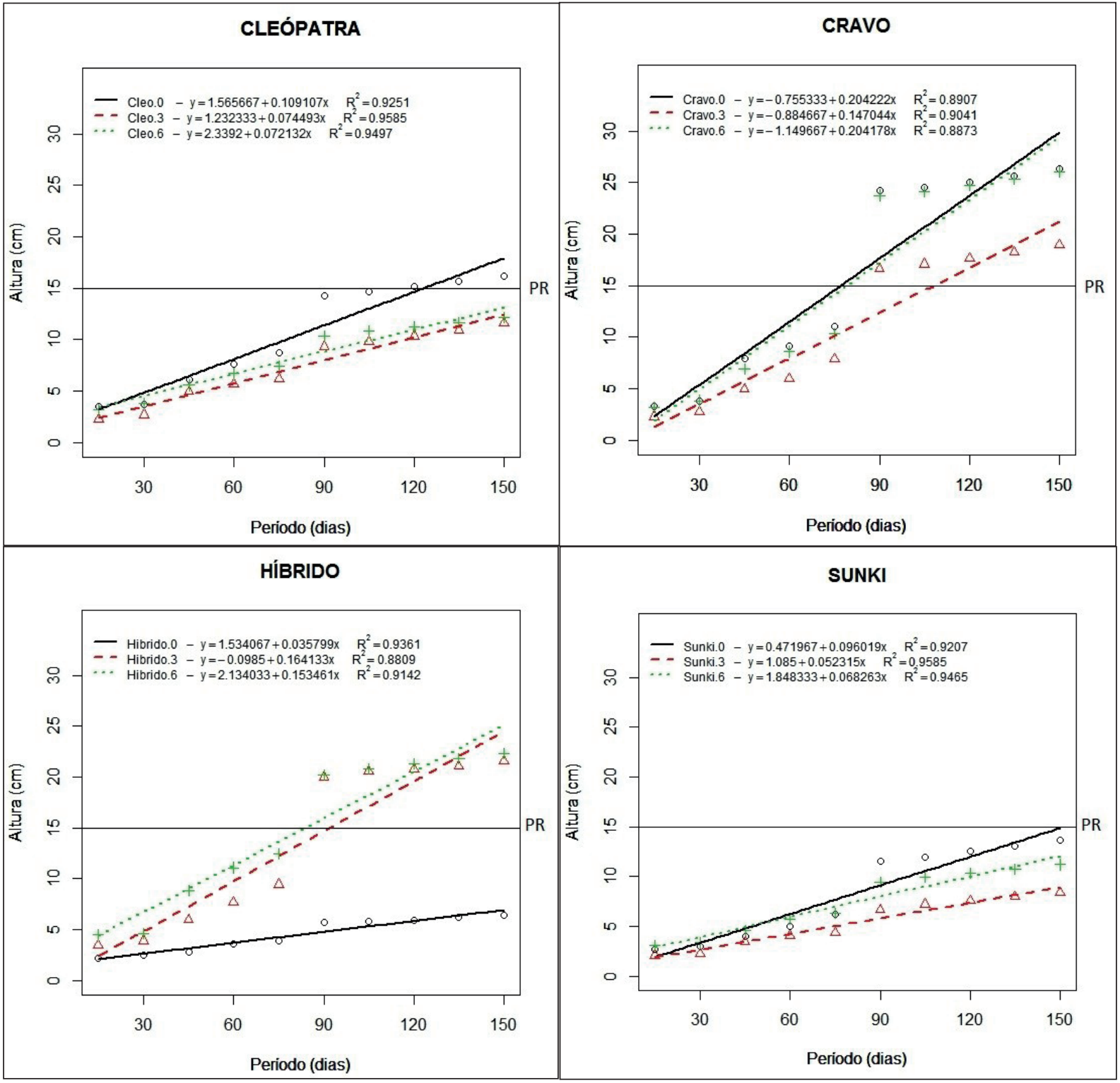

FIGURA 3: Altura de seedlings (plantas oriundas da germinação de sementes ou pés-francos) de variedades porta-enxerto de citros transferidos em diferentes alturas de planta (0,3 e $6 \mathrm{~cm})$, em dez períodos de avaliação. PR: Ponto de Repicagem. Lavras-MG, 2012. 
Quando a altura de transferência foi zero, ou seja, quando o cultivo dos seedlings deu-se diretamente em solução nutritiva, as maiores médias de massa seca de raiz, parte aérea e massa seca total foram constatadas no 'Cravo Santa Cruz', tendo esse superado estatisticamente as demais variedades porta-enxerto, embora a 'Sunki Tropical' tenha se aproximado do mesmo relativamente às referidas variáveis (Tabela 2). Girardi et al. ${ }^{18}$ avaliaram diferentes manejos de adubação na produção de mudas cítricas e não constataram diferença na massa de matéria seca do sistema radicular sob os diferentes manejos estudados.

As plantas do híbrido TSKC x (LCR x TR) - 059 e do limoeiro 'Cravo Santa Cruz', quando transferidas para solução nutritiva com $3 \mathrm{~cm}$ de altura, apresentaram maior massa seca de raízes e massa seca total, superando as tangerineiras (Tabela 2). Em estudo realizado por Girardi et al. ${ }^{18}$, o uso de fertilizante de liberação controlada associado a fertirrigação diária levou à produção de plantas com maior massa de matéria seca.

Ainda analisando os resultados apresentados na Tabela 2, quando as plantas foram transferidas para solução nutritiva com $6 \mathrm{~cm}$ de altura, o limoeiro 'Cravo Santa Cruz' foi superior às demais variedades porta-enxerto no tocante à produção de massa seca de raiz, parte aérea e total. Em todas as alturas de transferência estudadas o híbrido TSKC x (LCR x TR) - 059 foi estatisticamente superior às demais variedades quando se calculou a relação entre massa seca de raiz e massa seca da parte aérea; isso indica um potencial dessa variedade híbrida em desenvolver raízes, o que é interessante quando se almeja uma melhor exploração do ambiente de cultivo pelo sistema radicular, otimizando a absorção dos nutrientes disponíveis.

A área foliar dos diferentes genótipos foi afetada pelas alturas de repicagem. Para as plantas cultivadas desde a germinação em solução nutritiva (altura zero), observou-se um melhor desempenho do 'Cravo Santa Cruz', que superou estatisticamente as demais variedades porta-enxerto, igualando-se, porém, à tangerineira 'Sunki Tropical'.

Quando as plantas foram transferidas para solução nutritiva com 3 e $6 \mathrm{~cm}$, o limoeiro 'Cravo Santa Cruz' foi estatisticamente superior às tangerineiras (Tabela 2). Em ensaio avaliando a produção do porta-enxerto cítrico limoeiro 'Cravo' no sistema de blocos prensados e substrato de casca de pinus em tubetes, Serrano et al. ${ }^{15}$ verificaram que os portaenxertos produzidos em blocos prensados apresentaram maior área foliar.

Neste estudo, o ciclo de desenvolvimento das variedades portaenxerto foi reduzido em 90 dias, quando comparado ao sistema convencional de produção de mudas (Figura 4). 
TABELA 2: Massa seca de raiz (MSraiz) e parte aérea (MSpa), massa seca total (MStotal), relação MSraiz/MSpa e área foliar (AF) de seedlings (plantas oriundas da germinação de sementes ou pés-francos) de variedades porta-enxerto de citros transferidos em diferentes alturas de planta para sistema de cultivo hidropônico. Dados expressos em gramas. Lavras-MG, 2012.

\begin{tabular}{|c|c|c|c|c|c|}
\hline \multirow{3}{*}{ Porta-enxertos* } & \multicolumn{5}{|c|}{ Alturas de transferência } \\
\hline & \multicolumn{5}{|c|}{$0 \mathrm{~cm}$} \\
\hline & MSraiz & MSpa & MStotal & MSraiz/MSpa & $\mathrm{AF}$ \\
\hline Tangerineira 'Sunki Tropical’ & $3,82 a b$ & $11,76 a b$ & $15,58 a b$ & $0,32 b$ & $70,84 a b$ \\
\hline Tangerineira ‘Cleópatra’ & $2,45 b$ & $5,49 \mathrm{bc}$ & $7,82 \mathrm{~b}$ & $0,45 b$ & $41,67 b$ \\
\hline Limoeiro ‘Cravo Santa Cruz’ & $6,87 a$ & $16,41 \mathrm{a}$ & $23,29 a$ & $0,42 \mathrm{~b}$ & $98,76 \mathrm{a}$ \\
\hline \multirow[t]{3}{*}{ Híbrido TSKC x (LCR x TR) - 059} & $2,33 b$ & $3,95 \mathrm{c}$ & $6,40 \mathrm{~b}$ & $0,59 a$ & $41,64 b$ \\
\hline & \multicolumn{5}{|c|}{$3 \mathrm{~cm}$} \\
\hline & MSraiz & MSpa & MStotal & MSraiz/MSpa & AF \\
\hline Tangerineira 'Sunki Tropical’ & $1,17 \mathrm{~b}$ & $3,47 a b$ & $4,64 b$ & $0,34 \mathrm{~b}$ & $32,97 \mathrm{~b}$ \\
\hline Tangerineira 'Cleópatra' & $0,79 \mathrm{~b}$ & $2,08 \mathrm{~b}$ & $2,87 \mathrm{~b}$ & $0,38 a b$ & $31,07 b$ \\
\hline Limoeiro ‘Cravo Santa Cruz’ & $5,17 a$ & $10,87 \mathrm{a}$ & $16,04 \mathrm{a}$ & $0,48 a b$ & $77,63 \mathrm{a}$ \\
\hline \multirow[t]{3}{*}{ Híbrido TSKC x (LCR x TR) - 059} & $6,03 \mathrm{a}$ & $10,81 \mathrm{a}$ & $16,84 \mathrm{a}$ & $0,56 \mathrm{a}$ & $47,29 a b$ \\
\hline & \multicolumn{5}{|c|}{$6 \mathrm{~cm}$} \\
\hline & MSraiz & MSpa & MStotal & MSraiz/MSpa & AF \\
\hline Tangerineira ‘Sunki Tropical’ & $1,21 \mathrm{c}$ & $3,12 b$ & $4,33 b$ & $0,39 b$ & $35,88 b$ \\
\hline Tangerineira ‘Cleópatra’ & $1,22 \mathrm{c}$ & $2,40 \mathrm{~b}$ & $3,62 b$ & $0,51 b$ & $34,11 b$ \\
\hline Limoeiro ‘Cravo Santa Cruz’ & $8,77 \mathrm{a}$ & $17,86 \mathrm{a}$ & $26,62 \mathrm{a}$ & $0,49 b$ & 93,28 a \\
\hline Híbrido TSKC x (LCR x TR) - 059 & $5,52 \mathrm{~b}$ & $7,87 \mathrm{~b}$ & $13,38 \mathrm{~b}$ & $0,70 \mathrm{a}$ & $50,21 \mathrm{ab}$ \\
\hline C.V. (\%) & 10,31 & 12,03 & 15,45 & 9,83 & 23,07 \\
\hline DMS & 3,11 & 7,63 & 10,59 & 0,20 & 44,98 \\
\hline
\end{tabular}

*Tangerineira 'Sunki Tropical' [Citrus sunki (Hayata) hort. ex Tanaka]; tangerineira ‘Cleópatra' (C. reshni hort. ex Tanaka); limoeiro 'Cravo Santa Cruz' (C. limonia Osbeck); TSKC: tangerineira 'Sunki' comum; LCR: limoeiro ‘Cravo'; TR: Poncirus trifoliata (L.) Raf.; Médias seguidas de mesmas letras, nas colunas dentro de cada altura de transferência, não diferem pelo teste de Tukey a $5 \%$ de probabilidade.

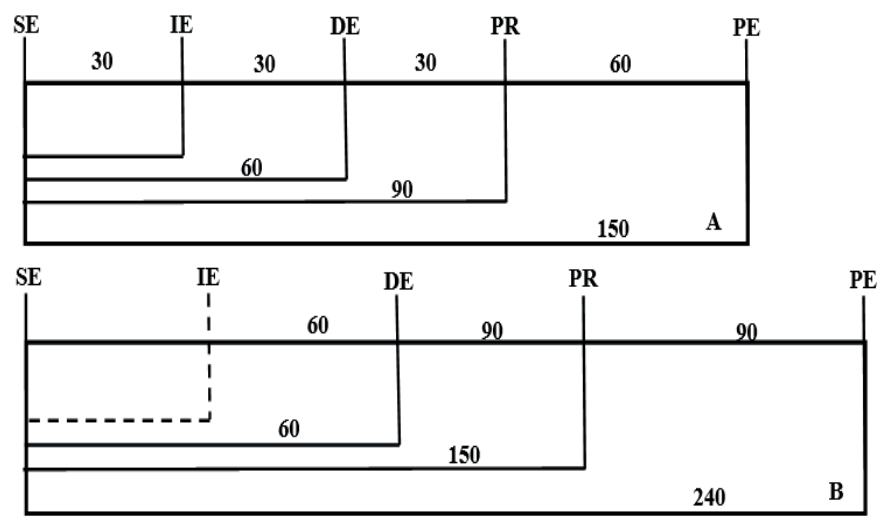

FIGURA 4: Comportamento de seedlings (plantas oriundas da germinação de sementes ou pés-francos) de variedades porta-enxerto de citros em sistemas de cultivo hidropônico (A) e convencional (Embrapa, 2011) (B), compreendendo as fases de semeadura (SE), início da emergência das plântulas (IE), desbaste (DE), ponto de repicagem (PR) e ponto de enxertia (PE). Lavras-MG, 2012. 


\section{CONCLUSÕES}

O sistema hidropônico é viável para a produção de porta enxertos cítricos.

A emergência de plântulas das tangerineiras 'Cleópatra' e 'Sunki Tropical' e do limoeiro 'Cravo Santa Cruz' foi maior em solução nutritiva, enquanto que o híbrido TSKC $\times($ LCR $\times$ TR) - 059 apresentou maior emergência em solução aquosa.

As tangerineiras estudadas podem ser semeadas já em solução nutritiva.

O limoeiro 'Cravo Santa Cruz' e o híbrido TSKC $\times(L C R \times T R)$ - 059, quando transferidos com $6 \mathrm{~cm}$ de altura para a solução nutritiva, apresentaram melhor desenvolvimento em altura e diâmetro. Estes produziram maior quantitativo de biomassa.

O limoeiro 'Cravo Santa Cruz' apresentou área foliar superior à das demais variedades porta-enxerto.

Em sistema de cultivo hidropônico, a produção dos porta-enxertos foi antecipada em 90 dias.

\section{AGRADECIMENTO}

À Coordenação de Aperfeiçoamento de Pessoal de Nível Superior (CAPES), pela concessão da bolsa de estudos.

\section{REFERÊNCIAS BIBLIOGRÁFICAS}

1. Fundecitrus, 2022. Reestimativa Da Safra De Laranja 2021/22 do Cinturão Citrícola de São Paulo e Triângulo/ Sudoeste Mineiro - Cenário em dezembro/2021. Disponível em: https://www.fundecitrus.com.br/ pdf/pes_relatorios/1221_Reestimativa_da_Safra_de Laranja.pdf.

2. Pompeu Junior, J. Porta-enxertos. In: Mattos Junior, D.; de Negri, JD, Pio RM, Pompeu Junior, J. (Org.). Citros. Campinas: Instituto Agronômico/ FUNDAG, 2005. p. 61-104.

3. Stuchi ES, Espinoza-Nunez E, Mourao FDA, Ortega $E M M$. Vegetative growth, yield and fruit quality of four mandarin and hybrid cultivars on four rootstocks. Rev. Bras. Frutic., Jaboticabal. 2008; 30: 741-47.

4. Empresa Brasileira de Pesquisa Agropecuária. Embrapa. Mudas de Citros. Disponível em: http:// sistemasdeproducao.cnptia.embrapa.br.
5. Campos SRF, Bezerra AR, Siqueira, DL. Ambiente Protegido: Olericultura, Citricultura e Floricultura, Cap. 4. Universidade Federal de Viçosa, Viçosa, MG, editores: Tiago Cavalheiro Barbosa et al., 2006. 194p.

6. Oliveira EAB. Viabilidade da produção de mudas cítricas em sistema hidropônico. 2007. 48p. Monografia (Graduação em Agronomia) Universidade Federal de Lavras, Lavras, MG.

7. Faquin V, Chalfun NNJ. "Hidromudas: Processo de produção de porta-enxerto de mudas frutíferas, florestais e ornamentais enxertadas em hidroponia". Patente: PI 0802792-7 A2 BRN.PI 0802792-7, 2011. Disponível em:< http://www.inpi.gov.br/menusuperior/pesquisas > Acessoado em: 28 jun 2012.

8. Menezes TP. Crescimento de porta-enxertos cítricos em sistema hidropônico. 2010. 63p. Dissertação (Mestrado em Fitotecnia) - Universidade 
Federal de Lavras, Lavras-MG.

9. Maguire JB. Speed of germination-aid in selection and evaluation for seedling emergence vigor. Crop Science, Madison. 1962; 2(2): 176-77.

10. Beadle DL. Growth analysis. In: Hall DO, Bolharnordenkampf HR, Leedoog RC, Long SP. Photosyntesis and production in a changing environment: a field and a laboratory manual. Landon: Pregaman Press, 1993; 36-46.

11. Ferreira DF. Análise estatística por meio do SISVAR para Windows 4.0 In: REUNIÃO ANUAL DA REGIÃO BRASILEIRA DA SOCIEDADE, INTERNACIONAL DA BIOMETRIA, 45, 2000, São Carlos. Anais... São Carlos, SP: UFSCAR, 2000; 255-258.

12. R DEVELOPMENT CORE TEAM. R: A language and envioronment for statistical computing. Viena: Computing RFS, 2010. Disponível em: http://www.Rproject.org. Acesso em: 12 julho 2012.

13. Jabur MA, Martins ABG. Influência de substratos na formação dos porta-enxertos: Limoeiro 'Cravo (Citrus limonia Osbeck) e Tangerineira 'Cleópatra' (Citrus reshni Hort. Ex Tanaka). Rev. Bras. Frutic., Jaboticabal. 2002; 24(2): 514-18.
14. Siqueira DL, Vasconcellos JFF, Dias DCFS, Pereira WE. Germinação de sementes de porta-enxertos de citros após o armazenamento em ambiente refrigerado. Rev. Bras. Frutic., Jaboticabal - SP. 2002; 24(2): 317-22.

15. Serrano LAL, Marinho CS, Barroso DG, Carvalho AJC. Sistema de blocos prensados e doses de adubo de liberação lenta na formação de porta-enxerto cítrico. Cienc Rural, Santa Maria. 2006; 36(2); 441-47.

16. Grassi Filho H. et al. Efeito de diferentes substratos no crescimento de mudas de limoeiro 'Cravo' até o ponto de enxertia. Revista Laranja. 2001; 22(1): 15766.

17. Teixeira PTL, Schäfer G, Souza PVD, Todeschini A. Desenvolvimento vegetativo e acúmulo de massa seca com a adubação de porta-enxertos cítricos cultivados em tubetes. Cienc Rural, Santa Maria. 2010; 40(12): 2603-07.

18. Girardi EA, Mourao FAA, Graf CCD, Olic FB. Influence of soluble and slow-release fertilizers on vegetative growth of containerized citrus nursery trees. J. Plant Nutr. 2005; 28:1465-80. DOI: 10.1080/01904160500201337. 